\title{
Food quality of mixed bacteria-algae diets for Daphnia magna
}

\author{
Heike M. Freese • Dominik Martin-Creuzburg
}

\begin{abstract}
Bacteria can comprise a large fraction of seston in aquatic ecosystems and can therefore significantly contribute to diets of filter-feeding zooplankton. To assess the effect of three heterotrophic bacteria (Flavobacterium sp., Pseudomonas sp. and Escherichia coli) on survival, growth and egg production of juvenile Daphnia magna during six-day growth experiments, five ratios of bacteria Scenedesmus obliquus mixtures were fed. Potential growth-limiting effects mediated by essential biochemicals were assessed upon supplementation of pure bacterial diets with a sterol (cholesterol) or a polyunsaturated fatty acid (EPA). Pure bacterial diets always had detrimental effects on Daphnia. However, cholesterol supplementation of Flavobacterium sp. enhanced growth
\end{abstract}

Guest editors: Marina Manca \& Piet Spaak / Cladocera:

Proceedings of the 9th International Symposium on Cladocera

H. M. Freese

Department of Biology, Microbial Ecology,

University of Konstanz, 78457 Konstanz, Germany

\section{H. M. Freese ( $\square)$}

Microbial Ecology and Diversity Research,

Leibniz Institut DSMZ Deutsche Sammlung von

Mikroorganismen und Zellkulturen, Inhoffenstraße 7B,

38124 Braunschweig, Germany

e mail: heike.freese@dsmz.de

D. Martin Creuzburg

Limnological Institute, University of Konstanz,

Mainaustrasse 252, 78464 Konstanz, Germany rates of Daphnia. Diets containing Pseudomonas impaired Daphnia growth even at low dietary proportions (20\%), indicating their toxicity. In contrast, Daphnia grew at relative high dietary proportions of Flavobacterium sp. and E. coli (80 50\%). In fact, diets containing small proportions of these heterotrophic bacteria (Flavobacterium $\leq 50 \%$, E. coli $20 \%$ ) even significantly increased Daphnia growth rates compared to pure algal diets, indicating a nutritional upgrading by these bacteria. Our results suggest that the relative contribution of bacteria and phytoplankton to total dietary carbon as well as their phylogenetic composition strongly influence Daphnia fitness and potentially other filter-feeding zooplankton under field conditions.

Keywords Flavobacterium sp. Pseudomonas sp. · Escherichia coli · Polyunsaturated fatty acids .

Sterols $\cdot$ Scenedesmus

\section{Introduction}

Aquatic systems are characterized by a complex food web, in which organic matter is transferred across different trophic levels. Cladocerans of the genus Daphnia often dominate the zooplankton in standing freshwater systems, and thus provide a crucial link between primary and secondary production (Peters \& de Bernardi, 1987). As non-selective filter-feeders, Daphnia do not only graze on phytoplankton but also 
on protozoa, bacteria and detritus (Jürgens, 1994; Cole et al., 2006). Heterotrophic bacteria often constitute a substantial part of the suspended particulate organic matter and have a key function by channelling organic carbon via incorporation into the food web (Azam et al., 1983; Biddanda et al., 2001). The aquatic bacterial communities consist of many different populations from different phyla (e.g. Rappe \& Giovannoni, 2003). Freshwater ecosystems are mainly dominated by $\beta$-proteobacteria, actinobacteria and bacteroidetes, but $\alpha$-proteobacteria, verrucomicrobia or planctomycetes can also be abundant (cf. Zwart et al., 2002, 2003; Newton et al., 2011). Daphnia can shape these microbial communities either by grazing on bacterivorous protozoans or by direct consumption of bacteria (Langenheder \& Jürgens, 2001; Degans et al., 2002; Pernthaler et al., 2004).

Although bacteria can be efficiently consumed by Daphnia (Gophen \& Geller, 1984; Brendelberger, 1991), their importance for Daphnia nutrition has been considered only recently. Analysis of stable isotope patterns and fatty acid biomarkers revealed that heterotrophic bacteria can significantly contribute to the diet of Daphnia species (Karlsson et al., 2003; Perga et al., 2006; Taipale et al., 2008, 2009). Bacteria generally have higher phosphorus to carbon (P:C) ratios than algae (Vadstein, 2000), and thus may sustain the high P demand of Daphnia (Andersen \& Hessen, 1991; Vrede et al., 1999; Hessen et al., 2002). Besides P, Daphnia also require essential biochemicals, like polyunsaturated fatty acids (PUFAs) and sterols (Brett \& Müller-Navarra, 1997; Martin-Creuzburg et al., 2005, 2009), which are important membrane components and serve as precursors for a number of bioactive molecules (Grieneisen, 1994; Harrison et al., 1997; Desvilettes et al., 1997; Martin-Creuzburg et al., 2007). Only few bacteria (methanotrophic bacteria, MOB) are known to produce sterols (e.g. Schouten et al., 2000; Volkman, 2003), but stable isotope analysis indicate that these bacteria may significantly contribute to Daphnia diet (Taipale et al., 2007, 2008). In addition, a MOB has been reported to enhance the reproduction of Daphnia, but the growth of Daphnia itself was not enhanced (Taipale et al., 2012). Only MOB parallel fed with limited quantities of phytoplankton partially support Daphnia growth (Deines \& Fink, 2011). Since sterol supplementation of bacterial diets (including a MOB) enhanced growth of D. magna (Martin-Creuzburg et al., 2011), the quality of bacteria as sole food source for Daphnia is likely low due to the absence of sterols in bacteria. Long chain PUFAs occur also not commonly in bacteria, although some, mostly marine psychrophilic bacteria did contain PUFAs (Russell \& Nichols, 1999; Okuyama et al., 2007). Consequently, Daphnia have been shown to be limited simultaneously by the absence of sterols and long chain PUFAs when feeding on cyanobacterial diet (Martin-Creuzburg et al., 2008, 2009). Thus, Daphnia are likely to be additionally restricted by the absence of these biochemicals when feeding on heterotrophic bacterial diets.

In natural environments, bacteria are unlikely the sole food source for Daphnia and instead are ingested along with phytoplankton species. The bacteria/phytoplankton proportions vary strongly among lakes and within lakes depending on nutrient state and season (0.02 16 bacterial-C/phytotplakton C; cf. Simon et al., 1992; Hessen et al., 2003). Here, to investigate the response of survival, growth and egg production of D. magna to differences in food quality of mixed bacteria-phytoplankton diets, we conducted standardized growth experiments with juvenile animals feeding on different bacteria provided either as sole food source or in combination with the green alga Scenedesmus obliquus. By experimentally increasing the proportion of different bacteria in the diet, we determined the bacteria to phytoplankton ratio at which Daphnia were negatively affected indicating the effect of declined food quality. We hypothesized that higher proportions of heterotrophic bacteria in the food suspension will restrict growth and egg production of Daphnia because of a limitation by sterols and PUFAs and that low proportions will either not affect or even benefit the animals. In addition, to assess the significance of a dietary sterol or PUFA deficiency caused by increasing the proportion of bacterial carbon, bacteria were supplemented either with cholesterol, the predominant animal sterol, or eicosapentaenoic acid (EPA), a long chain PUFA known to be of particular importance for Daphnia growth and reproduction.

\section{Materials and methods}

Cultivation of food organisms and preparation of food suspensions

Growth experiments were conducted with three strains of heterotrophic bacteria, i.e. Pseudomonas sp. DD1 
Table 1 Experimental setup and composition of food suspension

\begin{tabular}{|c|c|c|c|c|c|}
\hline Treatment & $\begin{array}{l}\text { Supplementation } \\
\text { of bacteria with }\end{array}$ & 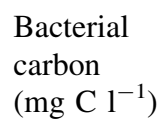 & $\begin{array}{l}\text { Abundance of } \\
\text { Flavobacterium sp. } \\
\text { DD5b }\left(\mathrm{ml}^{-1}\right)\end{array}$ & $\begin{array}{l}\text { Abundance of } \\
\text { Pseudomonas sp. } \\
\text { DD1 }\left(\mathrm{ml}^{-1}\right)\end{array}$ & $\begin{array}{l}\text { Abundance of } \\
\text { E. coli }\left(\mathrm{ml}^{-1}\right)\end{array}$ \\
\hline Starving & Nothing & 0 & 0 & 0 & 0 \\
\hline Scenedesmus & S. obliquus & 0 & 0 & 0 & 0 \\
\hline $20 / 80$ & S. obliquus & 0.4 & $4 \times 10^{6}$ & $4 \times 10^{6}$ & $4.4 \times 10^{6}$ \\
\hline $50 / 50$ & S. obliquus & 1 & $10 \times 10^{6}$ & $10 \times 10^{6}$ & $11.1 \times 10^{6}$ \\
\hline $80 / 20$ & S. obliquus & 1.6 & $16 \times 10^{6}$ & $16 \times 10^{6}$ & $17.8 \times 10^{6}$ \\
\hline Bacteria & Nothing & 2 & $20 \times 10^{6}$ & $20 \times 10^{6}$ & $22.2 \times 10^{6}$ \\
\hline+ Liposoms & Control liposomes & 2 & $20 \times 10^{6}$ & $20 \times 10^{6}$ & $22.2 \times 10^{6}$ \\
\hline +Cholesterol & $\begin{array}{l}\text { Cholesterol containing } \\
\text { liposomes }\end{array}$ & 2 & $20 \times 10^{6}$ & $20 \times 10^{6}$ & $22.2 \times 10^{6}$ \\
\hline$+\mathrm{EPA}$ & EPA containing liposomes & 2 & $20 \times 10^{6}$ & $20 \times 10^{6}$ & $22.2 \times 10^{6}$ \\
\hline
\end{tabular}

(NCBI: HQ113379) and Flavobacterium sp. DD5b (NCBI: HQ113381), both representing typical pelagic bacteria (Glöckner et al., 2000; Van der Gucht et al., 2005; Pearce et al., 2005), and E. coli (wild-type strain), which is regularly found in aquatic ecosystems (LaLiberte \& Grimes, 1982 and cited references; Hamelin et al., 2007). The bacterial strains were grown in mineral medium as described in Martin-Creuzburg et al. (2011), but with $20 \mathrm{mM}$ glucose and trace element solution SL12a $\left(2 \mathrm{ml} \mathrm{l}^{-1}\right)$ which was slightly modified with $1.1 \mathrm{~g} \mathrm{l}^{-1} \mathrm{FeCl}_{2} \cdot 4 \mathrm{H}_{2} \mathrm{O}, 0.07 \mathrm{~g} \mathrm{l}^{-1} \mathrm{ZnCl}_{2}$ and $0.1 \mathrm{~g} \mathrm{l}^{-1} \mathrm{MnCl}_{2}$ from SL 12 (Overmann et al., 1992). Bacteria were grown at $20^{\circ} \mathrm{C}$ and harvested daily in the late exponential and early stationary growth phase. Cells were centrifuged $\left(10 \mathrm{~min}, 5,000 \mathrm{~g}, 15^{\circ} \mathrm{C}\right)$, and resuspended in sterile-filtered and autoclaved Lake Constance water. Aggregates were dissolved by vortexing and short sonication. In order to add defined numbers (carbon concentrations) of bacteria to the growth experiments (Table 1), cell numbers were determined in a Helber counting chamber with a Zeiss Axiophot microscope. Carbon concentrations of defined bacterial cell numbers (i.e. bacterial carbon content) were estimated before the start of the experiment to adjust the carbon concentrations and were repeated during the experiment.

The green alga S. obliquus (SAG 276-3a), which contains sterols, but is deficient in C-20 PUFAs and thus of intermediate food quality, was used as food for stock cultures of D. magna and as a reference food in the growth experiments. It was grown in semicontinuous batch cultures as described in Martin-
Creuzburg et al. (2005) and harvested in the late exponential growth phase. Carbon contents of the autotrophic food suspensions were estimated from photometric light extinctions $(800 \mathrm{~nm})$ and from previously determined carbon-extinction equations.

\section{Daphnia growth experiments}

Stock cultures of $D$. magna (originally isolated by Lampert, 1991) were raised in filtered lake water (0.2$\mu \mathrm{m}$ pore-sized membrane filter) containing saturating concentrations of S. obliquus. Growth experiments were carried out with third-clutch neonates (born $\pm 6 \mathrm{~h}$ ) at $20^{\circ} \mathrm{C}$ in glass beakers filled with $200 \mathrm{ml}$ of filtered lake water $(<0.2 \mu \mathrm{m})$. Each treatment consisted of three replicates with six D. magna per beaker. Animals were transferred daily into new beakers with freshly prepared food suspensions over a period of 6 days, after which eggs were produced and the effect of different food qualities were pronounced.

Daphnia magna were raised on Pseudomonas sp. DD1, Flavobacterium sp. DD5b, or E. coli either as sole food source $\left(100: 0 \%\right.$, i.e. $\left.2 \mathrm{mg} \mathrm{C}^{-1}\right)$ or in different combination with $S$. obliquus (bacteria:phytoplankton carbon proportions: 80:20\%, 50:50\%, 20:80\%, 0:100\%; Table 1). The total carbon concentration in all treatments was $2 \mathrm{mg} \mathrm{C}{ }^{-1}$. In addition, pure bacterial food suspensions were supplemented with either $50 \mu \mathrm{l}$ of control liposomes (no sterols, no PUFAs), $50 \mu \mathrm{l}$ cholesterol-containing liposomes, or $50 \mu \mathrm{l}$ EPA-containing liposomes per beaker. Liposome stock suspensions were prepared as described in 
Martin-Creuzburg et al. (2008). The experiment was completed by a concomitant starvation treatment.

To estimate somatic growth rates of D. magna, subsamples of the experimental animals were taken at the beginning and at the end of the experiment, dried for $24 \mathrm{~h}$, and weighed on an electronic balance (Mettler Toledo XP2U; $\pm 0.1 \mu \mathrm{g}$ ). Somatic growth rates $(g)$ were determined as the increase in dry mass from day $0\left(M_{0}\right)$ to day $6\left(M_{6}\right)$ of the experimental period ( $t=6$ days) using the equation: $g=\left(\ln M_{6}\right.$ $\left.\ln M_{0}\right) t^{-1}$. Egg production was estimated by counting the eggs in the brood chambers of the animals at the end of the experiment.

\section{Biochemical analyzes of food suspensions}

For analysis of fatty acids and sterols, at least $5 \times 10^{9}$ cells were harvested by centrifugation, washed, freeze-dried, and stored at $-80^{\circ} \mathrm{C}$ at two time points. Total lipids were extracted thrice from freeze-dried samples with dichloromethane/methanol $(2: 1, \mathrm{v} / \mathrm{v})$ and the pooled cell-free extracts were evaporated to dryness with nitrogen. Lipid extracts were transesterified with $3 \mathrm{~mol} \mathrm{l}^{-1}$ methanolic $\mathrm{HCl}\left(60^{\circ} \mathrm{C}, 15 \mathrm{~min}\right)$ for analysis of fatty acids, or saponified with $0.2 \mathrm{~mol} \mathrm{l}^{-1}$ methanolic $\mathrm{KOH}\left(70^{\circ} \mathrm{C}, 1 \mathrm{~h}\right)$ for analysis of sterols. Subsequently, fatty acid methyl esters (FAMEs) were extracted three times with $2 \mathrm{ml}$ isohexane; the neutral lipids were partitioned into isohexane:diethyl ether $(9: 1, \mathrm{v} / \mathrm{v})$. The lipid-containing fraction was evaporated to dryness under nitrogen and resuspended in a volume of $1020 \mu \mathrm{l}$ iso-hexane. Lipids were analyzed by gas chromatography on a HP 6890 GC equipped with a flame ionization detector (FID) and a DB-225 (J\&W Scientific) capillary column to analyze FAMEs or with a HP-5 (Agilent Technologies) capillary column to analyze sterols. Details of GC configurations are given elsewhere (for fatty acids, Martin-Creuzburg et al. (2010); for sterols, Martin-Creuzburg et al. (2009)). Lipids were quantified (FID) by comparison to internal standards (C23:0 ME, 5 $\alpha$-cholestan) of known concentrations using multipoint standard calibration curves previously established for each compound (Sigma-Aldrich). The few non-purchasable lipid compounds were quantified using calibration curves of structurally related lipids with similar retention times. Lipids were identified by their retention times and their mass spectra, which were recorded with a gas chromatograph-mass spectrometer (Agilent Technologies, 7890A GC, 5975C inert MSD) equipped with a fused-silica capillary column (DB-225MS, J\&W for FAMEs; DB-5MS, Agilent for sterols). Sterol samples were analyzed in their free form and as their trimethylsilyl derivatives. Spectra were recorded between 50 and $600 \mathrm{amu}$ in the EI ionization mode. The limit of quantitation was $\sim 20 \mathrm{ng}$ for fatty acids or sterols. The absolute amount of each lipid was related to the particulate organic carbon (POC). At three times during the experiment, carbon, nitrogen $(\mathrm{N})$ and sulphur (S) were determined in duplicates from bacterial and algal suspensions concentrated in tin capsules for liquid samples using an elemental analyser (EuroEA3000, HEKAtech GmbH, Germany). For determination of particulate phosphorus, two aliquots per food suspension were collected on acid-rinsed polysulfone filters (HT-200; Pall) and digested with a solution of $10 \%$ potassium peroxodisulfate and $1.5 \%$ sodium hydroxide for $60 \mathrm{~min}$ at $121{ }^{\circ} \mathrm{C}$; soluble reactive phosphorus was determined using the molybdate-ascorbic acid method (Greenberg et al. 1985).

\section{Statistical analysis}

Somatic growth rates and egg production of Daphnia magna were analyzed using one-way analyses of variance (ANOVA) and post hoc tests (Tukey's HSD or Dunnett's T3 if variances were not equal (E. coli)). Treatments in which only one or none animal per beaker survived were excluded from the ANOVAs. Raw data met the assumptions for ANOVA. Statistical analyses were carried out using the General Linear Model module of SPSS 11 (SPSS Inc.).

\section{Results}

Characteristics of food sources

The three bacterial strains used for diet mixing experiments hardly differed in their $\mathrm{C}, \mathrm{N}$, and S-content per cell (Table 2). The phosphorus content per cell was lowest in E. coli and highest in Flavobacterium sp. Compared to $S$. obliquus, the bacteria were characterized by lower C:N (33 45\%) and C:P ratios (22 46\%), indicating a higher $\mathrm{N}$ and $\mathrm{P}$ content of the bacteria (Table 2). 
Table 2 Elemental composition and proportion of bacterial strains in comparison to the green algae Scenedesmus obliquus

\begin{tabular}{lllll}
\hline & Flavobacterium sp. DD5b & Pseudomonas sp. DD1 & E. coli & S. obliquus \\
\hline fg C/cell & $90.6 \pm 18.4$ & $81.9 \pm 24.1$ & $77.7 \pm 9.9$ \\
fg N/cell & $21.2 \pm 4.3$ & $21.9 \pm 5.2$ & $22.9 \pm 2.6$ \\
fg P/cell & $4.4 \pm 0.1$ & $3.0 \pm 0.02$ & $2.3 \pm 0.04$ \\
fg S/cell & $3.7 \pm 1.0$ & $3.3 \pm 1.0$ & $3.4 \pm 0.9$ & 7.0 \\
C:N (mol:mol) & 4.9 & 4.2 & 92 & 117 \\
C:P (mol:mol) & 64 & 82 & 4.3 \\
\hline
\end{tabular}

Data represent means of three replicates (for phosphate one) over time from which each two subsamples were measured \pm standard deviation

The fatty acid (FA) composition of the bacterial strains was dominated by saturated and monounsaturated fatty acids (Table 3 ). The fatty acid profiles of the $\gamma$-proteobacteria E. coli and Pseudomonas sp. were similar except for the saturated fatty acid 19:0 which only occurred in E. coli, a higher proportion of palmitoleic (16:1n-7) acid in Pseudomonas sp., and a higher proportion of cyclopropanoic acid (17:0 $)$ in E. coli. The FA profile of Flavobacterium sp. was more diverse than the profiles of the other two bacteria and contained also high amounts of branched-chain and hydroxy-fatty acids. PUFAs and sterols could not be detected in any of the bacterial strains. In contrast, S. obliquus contained high amounts of $18: 2 \mathrm{n}-6$ and 18:3n-3, but no PUFAs with more than 18 carbon atoms. Chondrillasterol (IUPAC name: (22E)-5 $\alpha-$ poriferasta-7,22-dien-3 $\beta$-ol; mean $\pm \mathrm{SD}: 58.3 \pm 3.8 \%$ ),

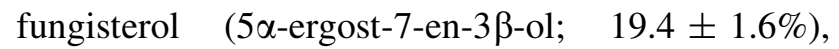
22-dihydrochondrillasterol ( $5 \alpha$-poriferast-7-en-3 $\beta$-ol; $9.7 \pm 0.9 \%$ ), and schottenol ( $5 \alpha$-stigmast-7-en-3 $\beta$-ol; $12.5 \pm 1.1 \%$ ) were the principal sterols found in the green alga.

The supplemented liposomes did not differ in their palmitic acid (16:0) and oleic acid (18:1n-9) content, which both are components of the phospholipids used to prepare the liposomes (Martin-Creuzburg et al., 2008). Liposomes prepared either in the presence of EPA or in the presence of cholesterol contained $14.5 \pm 1.9 \mu \mathrm{g}$ EPA or $11.2 \pm 1.1 \mu \mathrm{g}$ cholesterol per $50 \mu \mathrm{l}$ of liposome stock suspension, respectively.

\section{Survival of D. magna}

On a pure S. obliquus diet, all Daphnia survived the experimental period. Without food, about $40 \%$ of the animals survived (Fig. 1). On pure bacterial diets, survival differed depending on the bacterial strain used. In general, survival of D. magna was highest on Flavobacterium sp. ( $\sim 60 \%)$, intermediate on E. coli ( $\sim 15 \%)$, and lowest on Pseudomonas sp. (0\%). When provided in combination with $S$. obliquus, survival of D. magna decreased with increasing proportions of bacteria in the food suspension (Fig. 1). This decrease in survival was most pronounced with Pseudomonas sp.; none of the animals survived the experimental period when $\geq 50 \%$ of the available carbon was provided as Pseudomonas sp. In contrast, survival on diets containing increasing proportions of Flavobacterium sp. or E. coli was not reduced until $80 \%$ of the available carbon was bacterial carbon (Fig. 1). Cholesterol supplementation of a pure Flavobacterium sp. diet increased survival of D. magna, but cholesterol supplementation did not affect survival on the $\gamma$-proteobacteria. In contrast, survival on the $\gamma$-proteobacteria increased upon EPA supplementation (Fig. 1).

Somatic growth rates and egg production of D. magna

Somatic growth rates of $D$. magna were significantly affected by increasing the proportion of bacteria in their diet. Exchanging 20\% of the available carbon with Flavobacterium sp. or E. coli slightly but significantly increased somatic growth rates as compared to those obtained on a pure $S$. obliquus diet (Fig. 2a, c; Tukey's HSD (a) or Dunnett's T3 (c), $P<0.05$ following ANOVA: $F_{4,10}=1506$ (a), $F_{3,8}=220$ (c), both $\left.P<0.001\right)$. In general, however, somatic growth rates decreased with increasing proportions of bacterial dietary carbon. With Flavobacterium sp. and with E. coli, this decrease was significant at proportions $\geq 80 \%$ and with 
Table 3 Fatty acid content of the three bacteria Flavobacterium sp., Pseudomonas sp. and E. coli, and of the green alga Scene desmus obliquus

\begin{tabular}{|c|c|c|c|c|}
\hline & $\begin{array}{l}\text { Flavobacterium } \\
\text { (\% of total FA) }\end{array}$ & $\begin{array}{l}\text { Pseudomonas } \\
\text { (\% of total FA) }\end{array}$ & $\begin{array}{l}\text { E. coli } \\
\text { (\% of total FA) }\end{array}$ & $\begin{array}{l}\text { S. obliquus } \\
\text { (\% of total FA) }\end{array}$ \\
\hline 14:0 & $1.39 \pm 0.14$ & $0.46 \pm 0.12$ & $0.91 \pm 0.19$ & $0.98 \pm 0.11$ \\
\hline $15: 0$ & $9.33 \pm 0.16$ & n.d. & n.d. & n.d. \\
\hline i15:0 & $10.09 \pm 0.17$ & n.d. & n.d. & n.d. \\
\hline a15:0 & $1.41 \pm 0.00$ & n.d. & n.d. & n.d. \\
\hline $2 \mathrm{OH} \mathrm{15:0}$ & $4.88 \pm 0.06$ & n.d. & n.d. & n.d. \\
\hline $3 \mathrm{OH} 15: 0$ & $2.06 \pm 0.08$ & n.d. & n.d. & n.d. \\
\hline $15: 1 n>5$ & $2.16 \pm 0.10$ & n.d. & n.d. & n.d. \\
\hline $15: \ln 5$ & $2.12 \pm 0.09$ & n.d. & n.d. & n.d. \\
\hline 16:0 & $13.14 \pm 0.53$ & $32.06 \pm 0.48$ & $28.09 \pm 0.06$ & $22.62 \pm 0.82$ \\
\hline i16:0 & $4.80 \pm 0.09$ & n.d. & n.d. & n.d. \\
\hline $3 \mathrm{OH}$ i16:0 & $1.88 \pm 0.05$ & n.d. & n.d. & n.d. \\
\hline $3 \mathrm{OH}$ a16:0 & $3.07 \pm 0.08$ & n.d. & n.d. & n.d. \\
\hline $3 \mathrm{OH}$ 17:0 & $2.84 \pm 0.10$ & n.d. & n.d. & n.d. \\
\hline $16: \ln >7$ & $1.16 \pm 0.05$ & n.d. & n.d. & n.d. \\
\hline $16: 1 \mathrm{n} 7$ & $28.51 \pm 0.39$ & $36.68 \pm 0.61$ & $1.55 \pm 0.04$ & $0.34 \pm 0.09$ \\
\hline $16: 1 \mathrm{n}<7$ & $0.76 \pm 0.00$ & n.d. & $0.41 \pm 0.04$ & n.d. \\
\hline i17:0 & $1.50 \pm 0.01$ & n.d. & n.d. & n.d. \\
\hline $17: 0 \Delta$ & $2.04 \pm 0.26$ & $4.70 \pm 0.03$ & $24.77 \pm 0.01$ & n.d. \\
\hline $17: \ln 7$ & $3.34 \pm 0.05$ & n.d. & n.d. & n.d. \\
\hline 18:0 & $2.56 \pm 0.48$ & $2.03 \pm 0.02$ & $1.79 \pm 0.11$ & $3.76 \pm 0.27$ \\
\hline 18:1n 9/n 12 & $0.96 \pm 0.06$ & $24.06 \pm 0.04$ & $27.84 \pm 0.64$ & $26.5 \pm 0.51$ \\
\hline 19:0 $\Delta$ & n.d. & n.d. & $14.65 \pm 0.27$ & n.d. \\
\hline 18:1n 7 & n.d. & n.d. & n.d. & $0.41 \pm 0.13$ \\
\hline $18: 2 n 6$ & n.d. & n.d. & n.d. & $11.63 \pm 0.23$ \\
\hline $18: 3 n 3$ & n.d. & n.d. & n.d. & $30.60 \pm 0.97$ \\
\hline $18: 4 n 3$ & n.d. & n.d. & n.d. & $3.16 \pm 0.19$ \\
\hline
\end{tabular}

Data represent means of two (bacteria) or three (alga) replicates over time \pm standard deviation (n.d. not detectable, i.e. $<20$ ng)

Pseudomonas sp. somatic growth rates significantly decreased already with $20 \%$ of bacterial carbon (ANOVA: $F_{1,4}=644, P<0.001$; Fig. 2). Growth of Daphnia differed significantly in dependence of the fed bacterial phylotype, e.g. at $20 \%$ bacterial carbon, Pseudomonas sp. fed Daphnia grew significantly less than Flavobacterium sp. or E. coli fed Daphnia (Tukey's HSD, $P<0.05$ following ANOVA: $\left.F_{2,6}=1041\right)$ and at 50\%, E. coli fed Daphnia grew significantly less than Flavobacterium sp. fed Daphnia carbon (ANOVA: $F_{1,4}=27, P<0.01$ ). When provided as sole food source, all bacteria were highly detrimental for D. magna. On a pure Pseudomonas sp. diet, none of the animals survived the experimental period and on a pure $E$. coli diet, only animals of one replicate barely survived so that somatic growth rates could not be determined. Growth rates obtained on a pure Flavobacterium sp. diet were low, but significantly increased upon cholesterol supplementation up to growth rates obtained on a pure $S$. obliquus diet (Tukey's HSD, $P<0.05$ following ANOVA: $F_{4,10}=255$; Fig. 2d). Supplementation of Flavobacterium sp. with control liposomes or EPA-containing liposomes did not improve somatic growth rates. Liposome supplementation of E. coli slightly improved survival and thus somatic growth rates could be determined. The obtained growth rates, however, were low and not affected by cholesterol or 


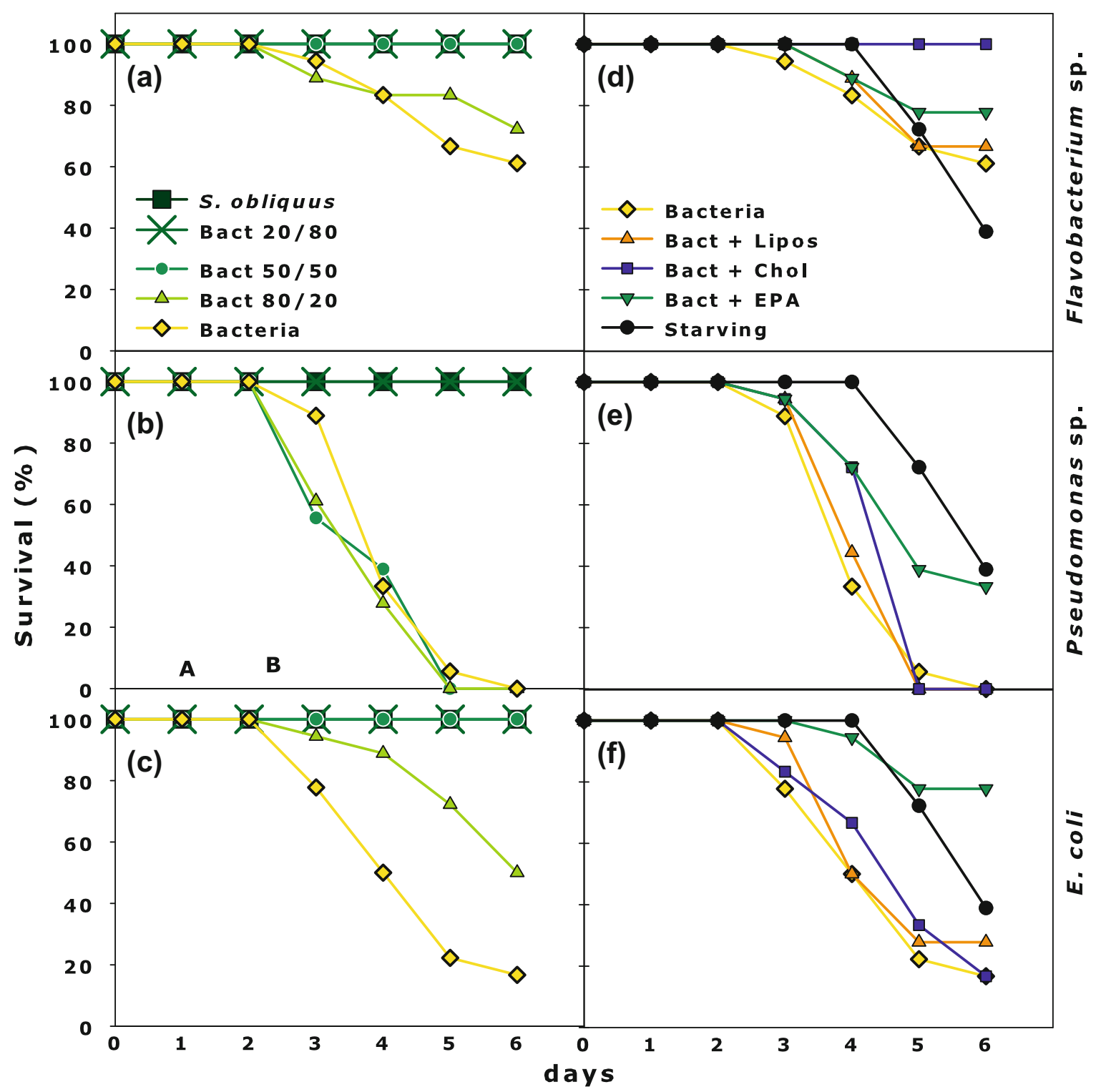

Fig. 1 Survival of juvenile D. magna exposed to different bacteria/Scenedesmus obliquus mixtures (a Flavobacterium sp., b Pseudomonas sp., and c E. coli) as well as to bacteria supplemented with cholesterol or EPA containing liposomes or control liposomes (Lipos) without added EPA or cholesterol

EPA supplementation. Liposome supplementation could also not improve somatic growth of D. magna on a pure Pseudomonas sp. diet (Fig. 2).

As observed for somatic growth, the detrimental effect of bacterial carbon on Daphnia egg production increased with decreasing proportions of dietary S. obliquus (Fig. 3). Animals raised on a diet consisting of $\geq 80 \%$ Flavobacterium sp., did not produce eggs within the experimental period and egg production was significantly reduced on a diet consisting of $\geq 50 \%$ E. coli (Tukey's HSD, $P<0.05$ following ANOVA: (d Flavobacterium sp., e Pseudomonas sp., and f E. coli) in comparison to starved animals. Data were calculated from the numbers of individuals which survived the experimental period of 6 days (means of $n \quad 3$ jars)

$\left.F_{2,6}=20\right)$. Animals exposed to Pseudomonas sp. did not produce eggs, even at the lowest dietary concentration. Animals raised on pure Flavobacterium sp. produced eggs upon cholesterol supplementation but less than produced on a pure $S$. obliquus diet.

\section{Discussion}

It has been recognized that heterotrophic bacteria are of poor food quality for Daphnia (Martin-Creuzburg 


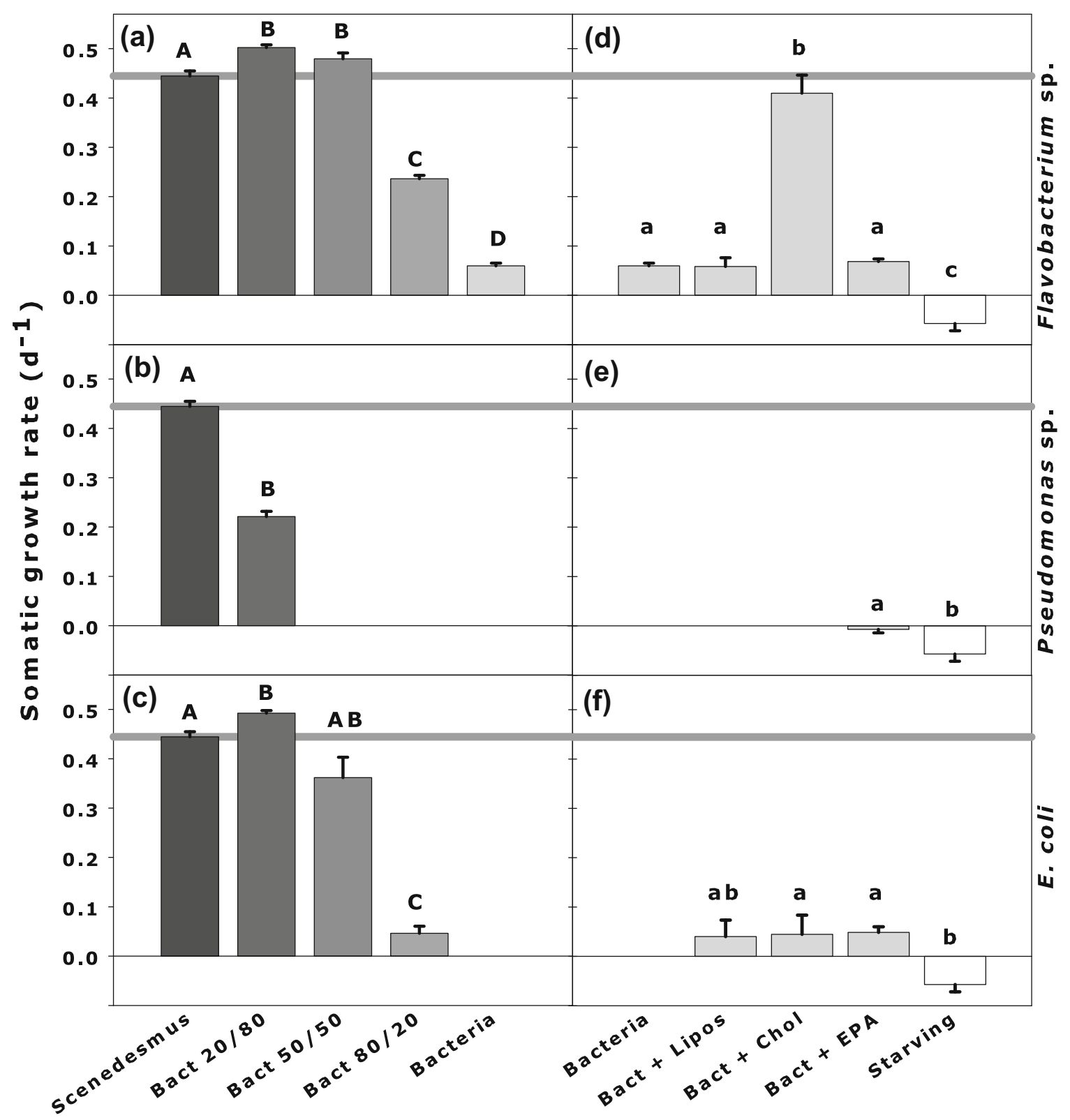

Fig. 2 Somatic growth rates of juvenile D. magna on different diets in comparison to starved animals. Daphnia were fed different bacteria/Scenedesmus obliquus mixtures (a Flavobac terium sp., b Pseudomonas sp., and c E. coli) as well as bacteria supplemented with cholesterol or EPA containing liposomes or control liposomes (Lipos) without added EPA or cholesterol (d Flavobacterium sp., e Pseudomonas sp., and f E. coli).

et al., 2011; Wenzel et al., 2012; Taipale et al., 2012). In a previous study, we have shown that this poor food quality is partially due to a dietary deficiency in sterols, as indicated by a growth-enhancing effect upon sterol supplementation of different bacterial diets (Martin-Creuzburg et al., 2011). However, bacteria are not only characterized by a deficiency in
Growth rates of animals fed $100 \%$ E. coli were excluded since only few animals of one replicate survived. The horizontal gray bar indicates growth rates of D. magna fed S. obliquus. Data are means of three replicates per treatment; error bars indicate SD. Bars labelled with the same letters are not significantly different (Tukey's HSD, $P<0.05$ following ANOVA)

sterols, they usually are also deficient in PUFAs (Russell \& Nichols, 1999; Okuyama et al., 2007), suggesting a co-limitation by sterols and PUFAs as has been shown for cyanobacterial diets (Martin-Creuzburg et al., 2009). Moreover, a number of bacterial strains isolated from aquatic habitats have been shown to produce toxic secondary metabolites that are active 


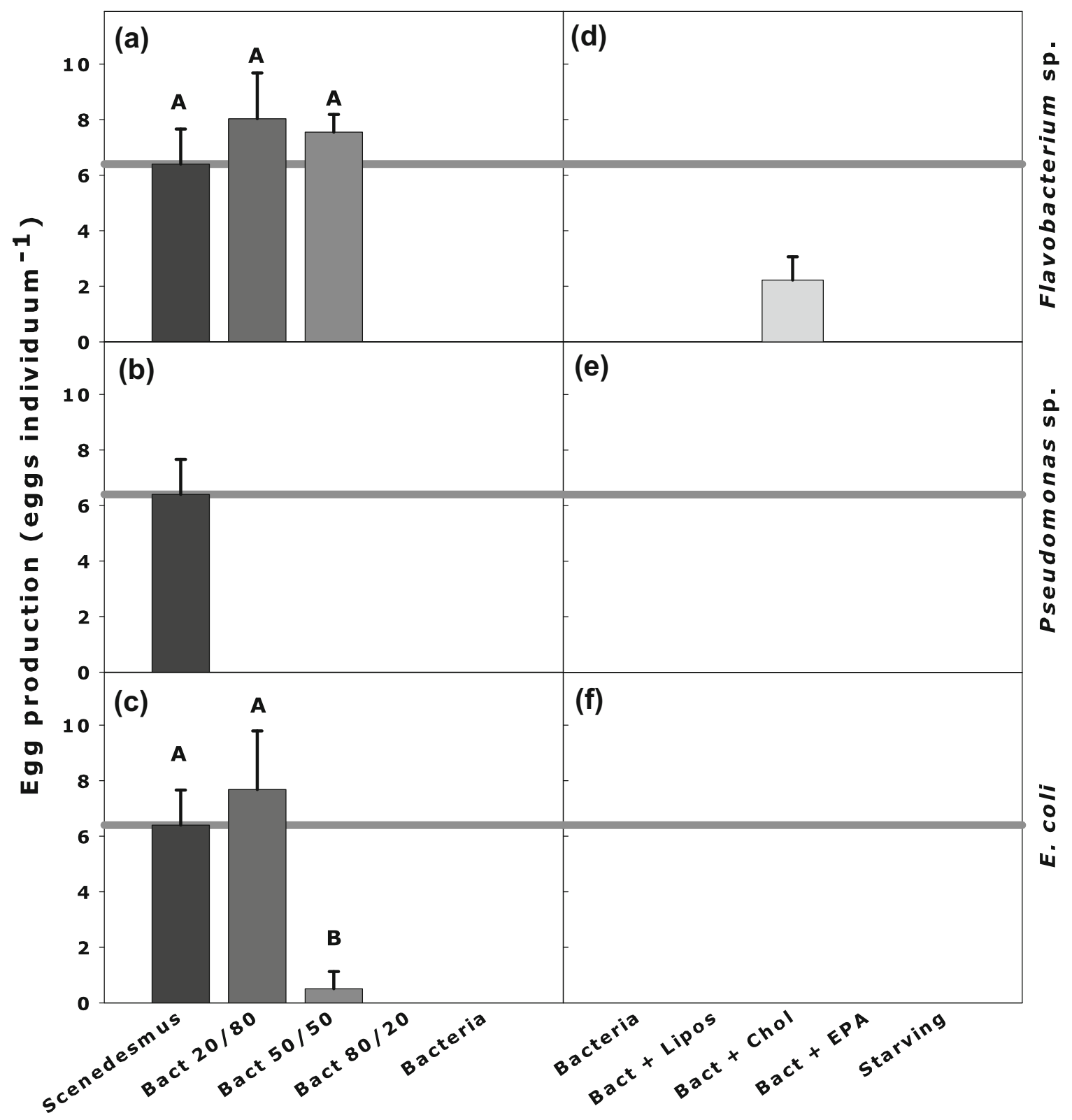

Fig. 3 Egg production of D. magna on different diets in comparison to starved animals. Daphnia were fed different bacteria/Scenedesmus obliquus mixtures (a Flavobacterium sp., b Pseudomonas sp., and c E. coli) as well as bacteria supplemented with cholesterol or EPA containing liposomes or control liposomes (Lipos) without added EPA or cholesterol

towards protozoans and metazoan grazers, among them D. magna (Matz \& Kjelleberg, 2005; Matz et al., 2008; Deines et al., 2009). High bacterial toxicity was also observed in our previous study, in which $D$. magna were exposed to a Hydrogenophaga sp. strain or a Pseudomonas sp. strain, which were previously isolated from the digestive tract of D. magna (MartinCreuzburg et al., 2011). The high toxicity of this (d Flavobacterium sp., e Pseudomonas sp., and $\mathbf{f}$ E. coli). The horizontal gray bar indicates number of eggs of $D$. magna fed $S$. obliquus. Data are means of three replicates per treatment; error bars indicate SD. Bars labelled with the same letters are not significantly different (Tukey's HSD, $P<0.05$ following ANOVA)

Pseudomonas sp. strain was corroborated in this study. When provided in combination with $S$. obliquus, growth and egg production of D. magna were significantly impaired even at low dietary concentrations of Pseudomonas sp. (20\% of dietary carbon). When Pseudomonas sp. was provided in higher concentrations, none of the animals survived the experimental period of 6 days. Pseudomonas spp. are known to 
produce a variety of toxic secondary metabolites (Gross \& Loper, 2009), suggesting that the negative effects of the isolated Pseudomonas sp. strain on the performance of $D$. magna we observed here and in our previous study were also caused by toxic secondary metabolites. Numerous Pseudomonas species/strains have been shown to act as pathogens in a wide range of invertebrates (Padmanabhan et al., 2005; e.g. Hilbi et al., 2007); detrimental effects on Daphnia have been reported for $P$. aeruginosa and $P$. entomophila (Le Coadic et al., 2012). However, Wenzel et al. (2012) reported that Daphnia can survive on diets containing high proportions of another Pseudomonas strain, indicating that Pseudomonas strains are not necessarily detrimental to consumers.

A somewhat lower mortality was observed on diets containing E. coli. Although E. coli is mostly classified as commensal, the potential of some strains to cause diseases in humans and other mammals has long been recognized. Less is known about pathogenicity of E. coli for invertebrates. However, E. coli strains were found to act as opportunistic pathogens in stressed and immunocompromised invertebrates, i.e. in old individuals and in individuals exposed to other pathogens [Millet \& Ewbank, 2004 (nematode); Broderick et al., 2006 (gypsy moth larvae)]. Since higher concentrations of E. coli than Pseudomonas sp. were required to cause the death of Daphnia, one may speculate that high amounts of a low quality food which likely reduced fitness of the animals increased Daphnia susceptibility to the pathogens. On the other hand, most $E$. coli strains from aquatic environments are non-pathogenic (e.g. Hamelin et al., 2007). The detrimental effect of higher proportions of $E$. coli may not be caused by a possible pathogenicity (or toxicity) but by a more pronounced response of Daphnia to their restricted food quality, since the effect of food quality increase with food quantity (Sterner, 1997).

The mortality of D. magna raised on diets containing Flavobacterium sp. was far less pronounced and presumably caused by nutritional challenges rather than toxicity. This at least was suggested by the growth-enhancing effect of sterol supplementation, indicating a sterol limitation of D. magna. In fact, somatic growth rates of D. magna on a pure Flavobacterium sp. diet increased upon sterol supplementation up to the growth rates obtained on a pure S. obliquus diet, showing that the absence of sterols is the major food quality constraint daphnids are confronted with while feeding on this bacterium. We propose that the negative effects associated with a dietary deficiency in sterols are on the tested $\gamma$-proteobacteria Pseudomonas sp. and E. coli masked by the toxicity of these bacteria.

It has been shown that daphnids feeding on cyanobacteria are simultaneously limited by sterols and PUFAs (Martin-Creuzburg et al., 2009; Sperfeld et al., 2012). In a previous study, we did not find clear evidence for such a co-limitation of Daphnia while feeding on heterotrophic bacteria (Martin-Creuzburg et al., 2011). In this study, supplementation of heterotrophic bacteria with EPA did not increase somatic growth rates or egg production of D. magna, suggesting that the absence of dietary PUFAs did not constrain the performance of the animals. This is somehow supported by the finding that somatic growth rates of D. magna on a pure Flavobacterium sp. diet, which contained neither EPA nor other PUFAs, increased upon sterol supplementation up to the level obtained on a pure algal (S. obliquus) diet. However, dietary PUFAs are indispensable for proper growth and reproduction of Daphnia, as has been shown by numerous studies, and thus it is rather unlikely that the performance of animals feeding on heterotrophic bacteria is not affected by the absence of dietary PUFAs. One might argue that the experimental design we used here, i.e. short-term growth experiments, are unsuitable to detect potential consequences associated with a dietary PUFA deficiency, because the animals may still rely on maternal PUFA reserves. However, the maternal PUFA supply was presumably low, because the animals were pre-raised on $S$. obliquus, a green alga deficient in long chain PUFAs. Although, these PUFAs can be produced and retained from shorter algal PUFAs by Daphnia (Kainz et al., 2004, Taipale et al., 2011), previous studies have repeatedly shown that even short-term feeding on PUFA deficient diets results in a limitation by PUFAs, provided that at least small amounts of dietary sterols are available (Martin-Creuzburg et al., 2009; Sperfeld et al., 2012). In our previous study, however, simultaneous supplementation of Flavobacterium sp. with cholesterol and EPA did also not reveal clear evidence for a PUFA limitation once sterol requirements were met (MartinCreuzburg et al., 2011). Overall, we did not find clear evidence for a limitation by EPA on bacterial diets within our 6 day lasting growth experiments. 
However, it remains to be tested whether a potential limitation by EPA can be detected when more than one reproduction cycle is considered, i.e. when potential PUFA reserves are exhausted (cf. Martin-Creuzburg et al., 2009). Interestingly, EPA supplementation of the $\gamma$-proteobacteria increased the survival of D. magna, suggesting that the detrimental effects mediated by these bacteria may have been alleviated by dietary EPA. We conclude that further (long-term) supplementation experiments are required before we are able to assess the role of PUFAs in determining the food quality of heterotrophic bacteria for Daphnia.

In the field, Daphnia do not feed solely on heterotrophic bacteria, and thus it is important to investigate at which dietary proportions bacteria become detrimental. By feeding D. magna with different combination of bacteria and the green alga $S$. obliquus, we show here that growth and egg production of D. magna are constraint when $8020 \%$, respectively, of the available carbon are represented by bacteria. This corroborates previous findings by Wenzel et al. (2012), who tested the food quality of a Pseudomonas strain in different combinations with Rhodomonas. They found that a $20 \%$ share of Rhodomonas in the food allowed survival of Daphnia and that a 50\% share enabled Daphnia to reproduce. Taipale et al. (2012) reported that high proportions of a type one methanotroph provided in different combinations with Cryptomonas resulted in high reproduction of Daphnia over 2 weeks. At limiting quantities of phytoplankton, MOB could even partially support Daphnia growth (Deines \& Fink, 2011). Thus, it appears that the dietary proportions at which bacteria become detrimental for Daphnia strongly depend on the bacterial phylotype and presumably also on the biochemical composition of the predominant algae.

Our results show that low proportions of heterotrophic bacteria in the food suspension can even increase somatic growth rates of Daphnia, as compared to a pure S. obliquus diet, suggesting that bacteria can provide essential nutrients not available in the green alga. Bacteria are often characterized by high P:C ratios and the bacteria in our experiment, especially Flavobacterium sp., had higher P:C ratios than $S$. obliquus (cf. Vadstein, 2000). However, the P:C-ratio of S. obliquus was already far above limiting levels (cf. DeMott, 1998; Persson et al., 2011) and thus a limitation of $D$. magna by phosphorus was rather unlikely in particular because daphnids seem to incorporate phosphorus from bacteria and algae with similar efficiencies (Wenzel et al., 2012). Nevertheless, low proportions of Flavobacterium sp. and E. coli increased somatic growth rates of D. magna, suggesting that other bacteriaderived nutrients were responsible for the observed upgrading of the $S$. obliquus diet. Vitamins, for instance, which can be produced by many bacteria, including members of the Flavobacteria and Enterobacteriaceae (Donderski \& Nowacka, 1992), are potentially important for Daphnia and it has been suggested already that vitamin addition can improve the food quality of S. obliquus for Daphnia (D'Agostino \& Provasoli, 1970; Mehdipour et al., 2011). The role of vitamins in determining food quality for Daphnia certainly requires further research.

Bacteria can comprise the major fraction of suspended organic matter in particular in oligo- to mesotrophic lakes (cf. Simon et al., 1992), but are quantitatively important also in eutrophic waters. High or increasing bacteria:phytoplankton ratios may constrain growth and reproduction of Daphnia even under field conditions. However, low proportions of algae may be enough to compensate for the nutritional deficiency of the bacteria and the bacteria algae mixtures may support Daphnia at least for a defined period of time. Especially members of Bacteroidetes, as well as of Actinobacteria (Taipale et al., 2012), even sustain Daphnia growth at higher bacterial proportions. Both bacterial groups are often numerically dominant in freshwater habitats, persist over seasons and seem to play an important role in the degradation of complex organic matter (Eiler \& Bertilsson, 2007; Newton et al., 2011; Parveen et al., 2011). Consequently, they potentially gain in importance for Daphnia nutrition at the end or between phytoplankton blooms (i.e. at higher bacteria:phytoplankton proportions).

Overall, our study highlight that feeding on heterotrophic bacteria can be associated with multiple challenges Daphnia have to cope with. Bacteria per se had detrimental effects on Daphnia because of their nutritional restraints or potential toxicity. Depending on the bacterial phylotype, however, Daphnia may be able to grow and reproduce even at high dietary proportions of bacteria, i.e. when provided in combination with eukaryotic phytoplankton. Moreover, low bacterial proportions may even upgrade the nutritional value of phytoplankton-dominated food. Thus, we propose that the relative contribution of bacteria and 
phytoplankton to total dietary carbon as well as their phylogenetic composition will strongly affect growth and survival of Daphnia and potentially other filterfeeding zooplankton under field conditions.

Acknowledgment We thank A. Wiese for technical assistance.

\section{References}

Andersen, T. \& D. O. Hessen, 1991. Carbon, nitrogen, and phosphorus content of freshwater zooplankton. Limnology and Oceanography 36: 807814.

Azam, F., T. Fenchel, J. G. Field, J. S. Gray, L. A. Meyer Reil \& F. Thingstad, 1983. The ecological role of water column microbes in the sea. Marine Ecology Progress Series 10: 257263.

Biddanda, B. A., M. Ogdahl \& J. Cotner, 2001. Dominance of bacterial metabolism in oligotrophic relative to eutrophic waters. Limnology and Oceanography 46: 730739.

Brendelberger, H., 1991. Filter mesh size of Cladocerans pre dicts retention efficiency for bacteria. Limnology and Oceanography 36: 884894.

Brett, M. \& D. Müller Navarra, 1997. The role of highly unsaturated fatty acids in aquatic foodweb processes. Freshwater Biology 38: 483499.

Broderick, N. A., K. F. Raffa \& J. Handelsman, 2006. Midgut bacteria required for Bacillus thuringiensis insecticidal activity. Proceedings of the National Academy of Sciences of the United States of America 103: 1519615199.

Cole, J. J., S. R. Carpenter, M. L. Pace, M. C. Van de Bogert, J. L. Kitchell \& J. R. Hodgson, 2006. Differential support of lake food webs by three types of terrestrial organic carbon. Ecology Letters 9: 558568.

D’Agostino, A. S. \& L. Provasoli, 1970. Dixenic culture of Daphnia magna, Straus. The Biological Bulletin 139: 485494.

Degans, H., E. Zollner, K. Van der Gucht, L. De Meester \& K. Jürgens, 2002. Rapid Daphnia mediated changes in microbial community structure: an experimental study. FEMS Microbiology Ecology 42: 137149.

Deines, P. \& P. Fink, 2011. The potential of methanotrophic bacteria to compensate for food quantity or food quality limitations in Daphnia. Aquatic Microbial Ecology 65: 197206.

Deines, P., C. Matz \& K. Jürgens, 2009. Toxicity of violacein producing bacteria fed to bacterivorous freshwater plank ton. Limnology and Oceanography 54: 13431352.

DeMott, W. R., 1998. Utilization of a cyanobacterium and a phosphorus deficient green alga as complementary resources by daphnids. Ecology 79: 24632481.

Desvilettes, C. H., G. Bourdier, C. H. Amblard \& B. Barth, 1997. Use of fatty acids for the assessment of zooplankton grazing on bacteria, protozoans and microalgae. Freshwa ter Biology 38: 629637.

Donderski, W. \& B. Nowacka, 1992. Production of B vitamins by planktonic bacteria isolated from the mesotrophic Lake Jasne. Journal of Islamic Academy of Sciences 5: 3238.
Eiler, A. \& S. Bertilsson, 2007. Flavobacteria blooms in four eutrophic lakes: Linking population dynamics of fresh water bacterioplankton to resource availability. Applied and Environmental Microbiology 73: 35113518.

Glöckner, F. O., E. Zaichikov, N. Belkova, L. Denissova, J. Pernthaler, A. Pernthaler \& R. Amann, 2000. Comparative $16 \mathrm{~S}$ rRNA analysis of lake bacterioplankton reveals glob ally distributed phylogenetic clusters including an abun dant group of actinobacteria. Applied and Environmental Microbiology 66: 50535065.

Gophen, M. \& W. Geller, 1984. Filter mesh size and food par ticle uptake by Daphnia. Oecologia 64: 408412.

Greenberg, A. E., R. R. Trussell \& L. S. Clesceri, 1985. Standard methods for the examination of water and wastewater. American Public Health Association, Washington, DC.

Grieneisen, M. L., 1994. Recent advances in our knowledge of ecdysteroid biosynthesis in insects and crustaceans. Insect Biochemistry and Molecular Biology 24: 115132.

Gross, H. \& J. E. Loper, 2009. Genomics of secondary metab olite production by Pseudomonas spp. Natural Product Reports 26: 14081446.

Hamelin, K., G. Bruant, A. El Shaarawi, S. Hill, T. A. Edge, J. Fairbrother, J. Harel, C. Maynard, L. Masson \& R. Brousseau, 2007. Occurrence of virulence and antimicro bial resistance genes in Escherichia coli isolates from different aquatic ecosystems within the St. Clair River and Detroit River areas, Applied and Environmental Microbi ology 73: 477484.

Harrison, P. J., N. Khan, K. Yin, M. Saleem, N. Bano, M. Nisa, S. I. Ahmed, N. Rizvi \& F. Azam, 1997. Nutrient and phytoplankton dynamics in two mangrove tidal creeks of the Indus River delta, Pakistan. Marine Ecology Progress Series 157: 1319.

Hessen, D. O., P. J. Færøvig \& T. Andersen, 2002. Light, nutri ents, and P:C ratios in algae: grazer performance related to food quality and quantity. Ecology 83: 18861898.

Hessen, D. O., T. Andersen, P. Brettum \& B. A. Faafeng, 2003. Phytoplankton contribution to sestonic mass and elemental ratios in lakes: implications for zooplankton nutrition. Limnology and Oceanography 48: 12891296.

Hilbi, H., S. S. Weber, C. Ragaz, Y. Nyfeler \& S. Urwyler, 2007. Environmental predators as models for bacterial patho genesis. Environmental Microbiology 9: 563575.

Jürgens, K., 1994. Impact of Daphnia on planktonic microbial food webs a review. Marine Microbial Food Webs 8: 295324.

Kainz, M., M. T. Arts \& A. Mazumder, 2004. Essential fatty acids in the planktonic food web and their ecological role for higher trophic levels. Limnology and Oceanography 49: 17841793.

Karlsson, J., A. Jonsson, M. Meili \& M. Jansson, 2003. Control of zooplankton dependence on allochthonous organic car bon in humic and clear water lakes in northern Sweden. Limnology and Oceanography 48: 269276.

LaLiberte, P. \& D. J. Grimes, 1982. Survival of Escherichia coli in lake bottom sediment. Applied and Environmental Microbiology 43: 623628 .

Langenheder, S. \& K. Jürgens, 2001. Regulation of bacterial biomass and community structure by metazoan and pro tozoan predation. Limnology and Oceanography 46: 121134. 
Le Coadic, M., M. Simon, A. Marchetti, D. Ebert \& P. Cosson, 2012. Daphnia magna, a host for evaluation of bacterial virulence. Applied and Environmental Microbiology 78: 593595.

Martin Creuzburg, D., A. Wacker \& E. von Elert, 2005. Life history consequences of sterol availability in the aquatic keystone species Daphnia. Oecologia 144: 362372.

Martin Creuzburg, D., S. A. Westerlund \& K. H. Hoffmann, 2007. Ecdysterold levels in Daphnia magna during a molt cycle: determination by radioimmunoassay (RIA) and liquid chromatography mass spectrometry (LC MS). General and Comparative Endocrinology 151: 6671.

Martin Creuzburg, D., E. von Elert \& K. H. Hoffmann, 2008. Nutritional constraints at the cyanobacteria Daphnia magna interface: the role of sterols. Limnology and Oceanography 53: 456468.

Martin Creuzburg, D., E. Sperfeld \& A. Wacker, 2009. Co limitation of a freshwater herbivore by sterols and poly unsaturated fatty acids. Proceedings of the Royal Society B: Biological Sciences 276: 18051814.

Martin Creuzburg, D., A. Wacker \& T. Basen, 2010. Interac tions between limiting nutrients: Consequences for somatic and population growth of Daphnia magna. Limnology and Oceanography 55: 25972607.

Martin Creuzburg, D., B. Beck \& H. M. Freese, 2011. Food quality of heterotrophic bacteria for Daphnia magna: evi dence for a limitation by sterols. FEMS Microbiology Ecology 76: 592601.

Matz, C. \& S. Kjelleberg, 2005. Off the hook how bacteria survive protozoan grazing. Trends in Microbiology 13: 302307.

Matz, C., J. S. Webb, P. J. Schupp, S. Y. Phang, A. Penesyan, S. Egan, P. Steinberg \& S. Kjelleberg, 2008. Marine biofilm bacteria evade eukaryotic predation by targeted chemical defense. PLoS ONE 3: e2744.

Mehdipour, N., M. Fallahi, G. Azari Takami, G. Vossoughi \& A. Mashinchian, 2011. Freshwater green algae Chlorella sp. and Scenedesmus obliquus enriched with B group of vita mins can enhance fecundity of Daphnia magna. Iranian Journal of Science \& Technology A2: 157163.

Millet, A. C. M. \& J. J. Ewbank, 2004. Immunity in Caeno rhabditis elegans. Current Opinion in Immunology 16: 49.

Newton, R. J., S. E. Jones, A. Eiler, K. D. McMahon \& S. Bertilsson, 2011. A guide to the natural history of fresh water lake bacteria. Microbiology and Molecular Biology Reviews 75: 1449.

Okuyama, H., Y. Orikasa, T. Nishida, K. Watanabe \& N. Mo rita, 2007. Bacterial genes responsible for the biosynthesis of eicosapentaenoic and docosahexaenoic acids and their heterologous expression. Applied and Environmental Microbiology 73: 665670 .

Overmann, J., U. Fischer \& N. Pfennig, 1992. A new purple sulfur bacterium from saline littoral sediments, Thi orhodotvibrio winogradskyi gen. nov. and sp. nov. Archives of Microbiology 157: 329335.

Padmanabhan, V., G. Prabakaran, K. P. Paily \& K. Balaraman, 2005. Toxicity of a mosquitocidal metabolite of Pseudo monas fluorescens on larvae \& pupae of the house fly, Musca domestica. Indian Journal of Medical Research 121: 116119.
Parveen, B., J. P. Reveilliez, I. Mary, V. Ravet, G. Bronner, J. F. Mangot, I. Domaizon \& D. Debroas, 2011. Diversity and dynamics of free living and particle associated betaprote obacteria and actinobacteria in relation to phytoplankton and zooplankton communities. FEMS Microbiology Ecology 77: 461476.

Pearce, D. A., C. J. van der Gast, K. Woodward \& K. K. New sham, 2005. Significant changes in the bacterioplankton community structure of a maritime Antarctic freshwater lake following nutrient enrichment. Microbiology 151: 32373248.

Perga, M. E., M. Kainz, B. Matthews \& A. Mazumder, 2006. Carbon pathways to zooplankton: insights from the com bined use of stable isotope and fatty acid biomarkers. Freshwater Biology 51: 20412051.

Pernthaler, J., E. Zollner, F. Warnecke \& K. Jürgens, 2004. Bloom of filamentous bacteria in a mesotrophic lake: identity and potential controlling mechanism. Applied and Environmental Microbiology 70: 62726281.

Persson, J., M. W. Wojewodzic, D. O. Hessen \& T. Andersen, 2011. Increased risk of phosphorus limitation at higher temperatures for Daphnia magna. Oecologia 165: 123129

Peters, R. H. \& R. de Bernardi, 1987. Daphnia. Memorie dell'Istituto Italiano di Idrobiologia 45: 1502.

Rappe, M. S. \& S. J. Giovannoni, 2003. The uncultured microbial majority. Annual Review of Microbiology 57: 369394.

Russell, N. J. \& D. S. Nichols, 1999. Polyunsaturated fatty acids in marine bacteria a dogma rewritten. Microbiology 145: 767779.

Schouten, S., J. P. Bowman, W. I. C. Rijpstra \& J. S. S. Damste, 2000. Sterols in a psychrophilic methanotroph, Meth ylosphaera hansonii. FEMS Microbiology Letters 186: 193195

Simon, M., B. C. Cho \& F. Azam, 1992. Significance of bac terial biomass in lakes and the ocean comparison to phytoplankton biomass and biogeochemical implications. Marine Ecology Progress Series 86: 103110.

Sperfeld, E., D. Martin Creuzburg \& A. Wacker, 2012. Multiple resource limitation theory applied to herbivorous con sumers: Liebig's minimum rule vs. interactive co limita tion. Ecology Letters 15: 142150.

Sterner, R. W., 1997. Modelling interactions of food quality and quantity in homeostatic consumers. Freshwater Biology 38: 473481

Taipale, S., P. Kankaala \& R. I. Jones, 2007. Contributions of different organic carbon sources to Daphnia in the pelagic foodweb of a small polyhumic lake: results from meso cosm (DIC) C 13 additions. Ecosystems 10: 757772.

Taipale, S., P. Kankaala, M. Tiirola \& R. I. Jones, 2008. Whole lake dissolved inorganic C 13 additions reveal seasonal shifts in zooplankton diet. Ecology 89: 463474.

Taipale, S., P. Kankaala, H. Hamalainen \& R. I. Jones, 2009. Seasonal shifts in the diet of Lake Zooplankton revealed by phospholipid fatty acid analysis. Freshwater Biology 54: 90104.

Taipale, S. J., M. J. Kainz \& M. T. Brett, 2011. Diet switching experiments show rapid accumulation and preferential retention of highly unsaturated fatty acids in Daphnia. Oikos 120: 16741682. 
Taipale, S. J., M. T. Brett, K. Pulkkinen \& M. J. Kainz, 2012. The influence of bacteria dominated diets on Daphnia magna somatic growth, reproduction, and lipid composi tion, FEMS Microbiology Ecology. doi:10.1111/j.1574 6941.2012.01406.x.

Vadstein, O., 2000. Heterotrophic, planktonic bacteria and cycling of phosphorus phosphorus requirements, com petitive ability, and food web interactions. In Schink, B. (ed.), Advances in Microbial Ecology, Vol. 16. Kluwer, New York: 115167.

Van der Gucht, K., T. Vandekerckhove, N. Vloemans, S. Cou sin, K. Muylaert, K. Sabbe, M. Gillis, S. Declerk, L. De Meester \& W. Vyverman, 2005. Characterization of bac terial communities in four freshwater lakes differing in nutrient load and food web structure. FEMS Microbiology Ecology 53: 205220.
Volkman, J. K., 2003. Sterols in microorganisms. Applied Microbiology and Biotechnology 60: 495506.

Vrede, T., T. Andersen \& D. O. Hessen, 1999. Phosphorus distribution in three crustacean zooplankton species. Limnology and Oceanography 44: 225229.

Wenzel, A., A. K. Bergström, M. Jansson \& T. Vrede, 2012. Survival, growth and reproduction of Daphnia galeata feeding on single and mixed Pseudomonas and Rhodo monas diets. Freshwater Biology 57: 835846.

Zwart, G., B. C. Crump, M. P. K. V. Agterveld, F. Hagen \& S. K. Han, 2002. Typical freshwater bacteria: an analysis of available 16S rRNA gene sequences from plankton of lakes and rivers. Aquatic Microbial Ecology 28: 141155.

Zwisler, W., N. Selje \& M. Simon, 2003. Seasonal patterns of the bacterioplankton community composition in a large meso trophic lake. Aquatic Microbial Ecology 31: 211225. 